\title{
Quantitative Analysis of 30 Drugs in Whole Blood by SPE and UHPLC-TOF-
} MS

\section{Dalsgaard $\mathrm{PW}^{*}$, Rode $\mathrm{AJ}^{1}$, Rasmussen $\mathrm{BS}^{1}$, Bjork $\mathrm{MK}^{1}$, Petersen $\mathrm{DI}^{2}$, Madsen $\mathrm{KA}^{2}$, Gammelgaard $\mathrm{B}^{2}$, Simonsen $\mathrm{KW}^{1}$ and Linnet $\mathrm{K}^{1}$}

${ }^{1}$ Department of Forensic Medicine, University of Copenhagen, Denmark

${ }^{2}$ Department of Pharmaceutics and Analytical Chemistry, University of Copenhagen, Denmark

*Corresponding author: Dalsgaard PW, Section of Forensic Chemistry, Department of Forensic Medicine, Faculty of Health Sciences, University of Copenhagen, Frederik V's vej 11, 3, DK-2100, Denmark, Fax: +45 3532 6085, Tel: +45 3532 6207, E-mail: petur.dalsgaard@sund.ku.dk

Citation: Dalsgaard PW, Rode AJ, Rasmussen BS, Bjork MK, Petersen DI, et al. (2013) Quantitative Analysis of 30 Drugs in Whole Blood by SPE and UHPLC-TOF-MS. J Forensic Sci Criminol 1(1): 101. doi: $10.15744 / 2348-9804.1 .101$

Received Date: June 27, 2013 Accepted Date: July 29, 2013 Published Date: August 01, 2013

\begin{abstract}
An Ultra-High Pressure Liquid Chromatography Time-of-Flight Mass Spectrometry (UHPLC-TOF-MS) method for quantitative analysis of 30 drugs in whole blood was developed and validated. The method was used for screening and quantification of common drugs and drugs of abuse in whole blood received from autopsy cases and living persons. The compounds included: alprazolam, amphetamine, benzoylecgonine, bromazepam, cathine, cathinone, chlordiazepoxide, cocaine, codeine, clonazepam, 7-aminoclonazepam, diazepam, nordiazepam, flunitrazepam, 7-aminoflunitrazepam, ketamine, ketobemidone, 3,4-Methylenedioxyamphetamine (MDA), 3,4-methylenedioxymethamphetamine (MDMA), methamphetamine, methadone, morphine, 6-monoacetylmorphine, nitrazepam, 7-aminonitrazepam, oxazepam, temazepam, tramadol, O-desmethyltramadol, and zolpidem. Blood samples $(200 \mu \mathrm{L})$ were subjected to Solid Phase Extraction (SPE). Target drugs were quantified using a Waters ACQUITY UPLC system coupled to a Waters SYNAPT G2 TOF-MS apparatus. Extraction recoveries ranged from $41 \%$ (7-aminoclonazepam) to $111 \%$ (ketamine) and matrix effects ranged from -13\% (temazepam) to 50\% (7-aminonitrazepam). For all compounds, a quadratic polynomial was applied for fitting the calibration curves. Lower Limits of Quantification (LOQ) ranged from 0.005 to $0.05 \mathrm{mg} / \mathrm{kg}$. Satisfactory precisions below $15 \%$ and accuracies within $85-115 \%$ were obtained for all compounds at concentrations exceeding the LOQ. In conclusion, we present a validated UHPLC-TOF-MS method for simultaneous quantification of 30 drugs in whole blood with a run time of 15 min using $200 \mu \mathrm{L}$ of whole blood.
\end{abstract}

Keywords: Drugs of abuse; UHPLC-TOF-MS; Whole blood; SPE; Quantification

\section{Introduction}

In toxicology, the usual approach is to screen for the presence of drugs and subsequently carry out a quantification of positive findings. Screening procedures may be based on immunoassay techniques, GC-MS, HPLC-DAD, LC-tandem mass spectrometry (LC-MS/MS), LC-ion trap mass spectrometry or LC-high resolution mass spectrometry as Time-of-Flight (TOF) or Orbitrap Fourier- transform mass spectrometry [110]. Quantitative determination is usually based on GC-MS or LC- MS/MS approaches [11]. Generally, if screening and quantification can be combined, a more efficient approach is attained. For optimal quantification, deuterated internal standards are usually required, so in practice it is not possible to combine general screening for several hundred compounds with quantification of all compounds that might be found in one analytical run. However, it might be possible to quantify a limited number of frequently occurring compounds, say about 30 compounds. In the present study we were interested in investigating the ability of a LC-TOF system to simultaneously carry out screening for a wide range of compounds as previously described and quantification of a more limited, frequently occurring subset of compounds [12]. Samples were prepared using fully automated Solid Phase Extraction (SPE) [12-14], and the compounds were separated using Ultra-High Pressure Liquid Chromatographic (UHPLC) chromatographic conditions as previously described [15-17]. Focus was on a comparison of Lower Limits of Quantification (LLOQ), precision, accuracy and dynamic range with those of the standard technique of LC-MS/MS for quantitative analysis. The results were primarily related to those recently reported by Bjork, et al. [13]. based on a UHPLC-MS/MS method for 31 commonly occurring medicinal and illicit drugs.

\section{Methods}

\section{Chemicals and reagents}

The following compounds were purchased as certified 
reference solutions from Lipomed $\mathrm{GmbH} \quad(\mathrm{Bad}$ Sackingen, Germany): alprazolam, amphetamine, methamphetamine, methylenedioxyamphetamine (MDA), methylenedioxymethamphetamine (MDMA), morphine, 6acetylmorphine (6-AM), codeine, cocaine, benzoylecgonine, methadone, bromazepam, clonazepam, flunitrazepam, nordiazepam, 7-aminonitrazepam, 7-aminoclonazepam, 7-aminoflunitrazepam, 7-aminoflunitrazepam-d3 and flunitrazepam-d3. From Cerilliant (Round Rock, Texas, USA) we obtained the following substances: cathine, cathinone, ketamine, amphetamine-d5, codeine- $\mathrm{d} 6$, cocaine- $\mathrm{d} 3$, chlordiazepoxide- $\mathrm{d} 5$, benzoylecgonine- $\mathrm{d} 8$, ephedrine-d3, 6-AM-d6, ketamine- $\mathrm{d} 4$, methadone- $\mathrm{d} 3$, methamphetamine-d5, morphine- $\mathrm{d} 6$, MDA- $\mathrm{d} 5$, zolpidem- $\mathrm{d} 6$, MDMA-d5, tramadol-C13-d3, O-desmethyltramadol-d6, diazepam-d5, nordiazepam-d5, nitrazepam-d5, oxazepam-d5, alprazolam-d5, clonazepam-d4, 7-aminoclonazepam-d4 and temazepam-d5. We obtained 7-aminonitrazepam-d5 and bromazepam-d4 from Toronto Research Chemicals (Toronto, Canada). All the reference standards were of $\geq 98 \%$ purity. Methanol and acetonitrile (LC-MS grade) were obtained from Fisher Scientific (Leicestershire, UK). Aqueous ammonia (25\%) solution was obtained from Merck (Darmstadt, Germany). Purified water was obtained with a Milli-Q system (Millipore, Denmark). The mobile phase used for the LC system was prepared weekly. Mobile phases were solvent A (5 $\mathrm{mM}$ ammonium formate, adjusted to $\mathrm{pH} 3$ using formic acid) and $\mathrm{B}$ (acetonitrile containing $0.1 \%(\mathrm{v} / \mathrm{v})$ formic acid).

\section{Samples}

We performed the analyses on whole blood stabilized with sodium fluoride and potassium oxalate. Investigations of matrix effects and extraction efficiency were based on negative authentic samples (pre-screened for all kinds of licit and illicit drugs received by the laboratory, either from autopsy cases or from living persons). The whole blood was stored at $-20^{\circ} \mathrm{C}$ until use.

\section{Preparation of standard solutions, calibrators and quality control (QC) samples}

A stock solution containing a mixture of all non-deuterated standards at a concentration of $20 \mathrm{mg} / \mathrm{L}$ was prepared in methanol. From this stock, three working solutions were prepared in water, at concentrations of $5 \mathrm{mg} / \mathrm{L}, 0.5 \mathrm{mg} / \mathrm{L}$ and $0.05 \mathrm{mg} / \mathrm{L}$, respectively. The stock solution was stored at $-20^{\circ} \mathrm{C}$; working solutions were stored at $-80^{\circ} \mathrm{C}$. A single Internal Standard solution (IS), containing the deuterated analogues in methanol at a concentration of $0.4 \mathrm{mg} / \mathrm{L}$, was prepared, divided into aliquots of $1000 \mu \mathrm{L}$ and kept at $-80^{\circ} \mathrm{C}$. Calibrators were made by spiking $0.200 \mathrm{~g}$ of pooled whole blood with 20 $\mu \mathrm{L}$ of standard working solutions, yielding final calibration concentrations of $0.0050,0.05$, and $0.5 \mathrm{mg} / \mathrm{kg}$. Two levels of quality control (QC) samples containing all compounds were prepared in pooled whole blood at concentrations of 0.02 and $0.5 \mathrm{mg} / \mathrm{kg}$ and stored at $-20^{\circ} \mathrm{C}$. An aliquot $(20 \mu \mathrm{L})$ of IS was added to all calibrators, QCs, and samples.

\section{Solid Phase Extraction}

SPE was performed on a Tecan Freedom EVO 200 robotic platform (Tecan, Mannedorf, Switzerland) fitted with a vacuum station for solid phase extraction [14]. Polymeric mixed-mode cation exchange resin Strata-X-C SPE cartridges $(30 \mathrm{mg}, 2$ $\mathrm{mL}$ ) were from Phenomenex (Torrance, CA). An aliquot (20 $\mu \mathrm{L}$ ) of IS was added to $0.200 \mathrm{~g}$ of each whole blood sample following dilution of the samples with $800 \mu \mathrm{L}$ of $1 \%$ formic acid in water. The samples were centrifuged at $1000 \mathrm{~g}$ for 10 $\mathrm{min}$. The supernatant was loaded onto pre-conditioned SPE columns (pre-conditioned and equilibrated with methanol followed by water). Columns were washed consecutively with $900 \mu \mathrm{L}$ water, followed by $2 \%$ formic acid in $5 \%$ methanol and finally with $250 \mu \mathrm{L}$ of methanol. Elution was performed by the addition of $500 \mu \mathrm{L}$ of freshly prepared acetonitrile containing $8 \%(\mathrm{v} / \mathrm{v})$ ammonia solution. A portion $(400 \mu \mathrm{L})$ of the eluate was evaporated to dryness by a gentle flow of nitrogen heated to $40^{\circ} \mathrm{C}$. Reconstitution was achieved by the addition of $40 \mu \mathrm{L}$ of acidified methanol (25\% methanol in water containing $0.1 \%$ formic acid) to the dry residue.

\section{LC chromatographic conditions}

The chromatography was performed using an ACQUITY UPLC system (Waters Corporation, Milford, USA) [15-17]. The column used was a $150 \mathrm{~mm} \times 2.1 \mathrm{~mm}, 1.8 \mu \mathrm{m}$ ACQUITY UPLC HSS C18, which was maintained at a column temperature of $50^{\circ} \mathrm{C}$ and eluted at a constant flow rate of $0.4 \mathrm{~mL} / \mathrm{min}$. The gradient was $13-13 \%$ solvent B (0-0.5 min), $13-50 \%$ solvent $B$ ( $0.5-10 \mathrm{~min}), 50-95 \%$ solvent $B(10-10.75 \mathrm{~min})$; the column was then flushed with $95 \%$ solvent $B$ (10.75-12.25 min). The total run time was $15 \mathrm{~min}$. The injection volume was 15 $\mu \mathrm{L}$. A methodology overview is shown in Table 1, and a chromatogram of all 30 analytes is presented in Figure 1.

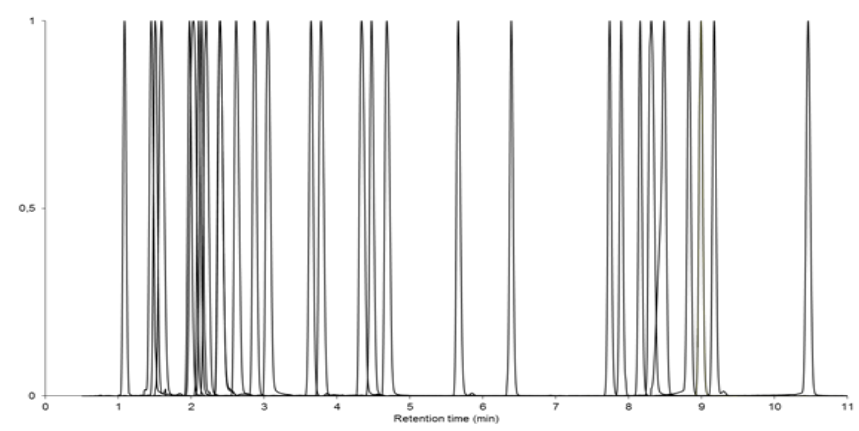

Figure 1: Chromatogram of 30 compounds.

\section{Mass spectrometry}

Mass spectrometry was performed using a SYNAPT G2 (Waters MS Technologies, Manchester, UK) orthogonal acceleration Quadrupole Time-of-Flight mass spectrometer. The mass spectrometer was operated in positive ion mode with electrospray ionisation (Z-spray). The nebulisation gas was set to $800 \mathrm{~L} / \mathrm{h}$ at a temperature of $550^{\circ} \mathrm{C}$. The cone gas was set to $10 \mathrm{~L} / \mathrm{h}$ and the source temperature to $120^{\circ} \mathrm{C}$. The capillary voltage and the cone voltage were set to 300 and $20 \mathrm{~V}$, respectively. Argon was used as the collision gas. For the MS ${ }^{\mathrm{E}}$ 
experiment, two acquisition functions with different collision energies were used in the trap collision cell. The low energy function (Function 1) was set to $4 \mathrm{eV}$, and the high energy function (Function 2) was set to use a collision energy ramp from 10-40 eV. The SYNAPT G2 was operated in V optics mode (resolution mode) with $>18,000$ at full width at half maximum at $m / z 556$. The data acquisition rate was $0.15 \mathrm{sec} /$ scan in both functions, with $0.024 \mathrm{sec}$ interscan delay; data was collected from $0.5 \mathrm{~min}$ to $13 \mathrm{~min}$. The mass spectrometer was calibrated to $<2 \mathrm{mDa}$ mass error prior to each batch. All analyses were acquired using Lock Spray to ensure accuracy and reproducibility; leucine-enkephalin was used as the lock mass $(\mathrm{m} / z 556.2771)$ at a concentration of $400 \mathrm{ng} / \mathrm{mL}$ and a flow rate of $50 \mu \mathrm{L} / \mathrm{min}$. Data were collected in centroid mode from $m / z 50-950$. A methodology overview is shown in Table 1 .

\begin{tabular}{|c|c|}
\hline \multicolumn{2}{|l|}{ Chromatography } \\
\hline $\begin{array}{l}\text { Liquid chromatog- } \\
\text { raphy system: }\end{array}$ & Waters ACQUITY UPLC \\
\hline Column: & $\begin{array}{l}\text { Waters ACQUITY }{ }^{\circ} \text { HSS C18 }(2.1 \times 150 \mathrm{~mm}, 1.8 \\
\mu \mathrm{m})\end{array}$ \\
\hline $\begin{array}{l}\text { Column tempera- } \\
\text { ture: }\end{array}$ & $50^{\circ} \mathrm{C}$ \\
\hline Injection volume: & $15 \mu \mathrm{L}$ \\
\hline Solvent A: & $\begin{array}{l}5 \mathrm{mM} \text { ammonium formate, adjusted to } \mathrm{pH} 3 \text { using } \\
\text { formic acid }\end{array}$ \\
\hline Solvent B: & Acetonitrile containing $0.1 \%(\mathrm{v} / \mathrm{v})$ formic acid \\
\hline \multirow[t]{4}{*}{ Gradient: } & $13-13 \%$ solvent $B(0-0.5 \mathrm{~min})$ \\
\hline & $13-50 \%$ solvent B $(0.5-10 \mathrm{~min})$ \\
\hline & $50-95 \%$ solvent B (10-10.75 min) \\
\hline & 95-95\% solvent B (10.75-12.25 min) \\
\hline Flow rate: & $0.4 \mathrm{~mL} / \mathrm{min}$ \\
\hline \multicolumn{2}{|l|}{ Mass Spectrometry } \\
\hline Mass spectrometer: & Waters SYNAPT G2 \\
\hline $\begin{array}{l}\text { Ionisation } \\
\text { mode: }\end{array}$ & Electrospray +ve \\
\hline Capillary voltage: & $300 \mathrm{~V}$ \\
\hline Cone voltage: & $20 \mathrm{~V}$ \\
\hline $\begin{array}{l}\text { Desolvation tem- } \\
\text { perature: }\end{array}$ & $550^{\circ} \mathrm{C}$ \\
\hline Desolvation gas: & $800 \mathrm{~L} / \mathrm{h}$ \\
\hline Source temperature: & $120^{\circ} \mathrm{C}$ \\
\hline Data acquisition: & $\mathrm{MS}^{\mathrm{E}}$ centroid (data independent acquisition) \\
\hline Function 1: & $4 \mathrm{eV}$ \\
\hline Function 2: & Ramp $10-40 \mathrm{eV}$ \\
\hline Mass ange: & $50-950 \mathrm{Da}$ \\
\hline Resolution: & $>18,000 @ 556$ m/z (resolution mode) \\
\hline Lock Spray: & Leucine encephalin $[\mathrm{M}+\mathrm{H}]^{+}=\mathrm{m} / \mathrm{z} 556.2771$ \\
\hline
\end{tabular}

Table 1: Methodology overview.

TargetLynx software was used for quantitative data processing (Waters Corporation, Milford, USA). The analytes were identified by the exact mass of the precursor ion and the retention time. Tolerance was set to $5 \mathrm{mDa}$ for the precursor ion and +/- $0.2 \mathrm{~min}$ for the retention time. Quantification was performed by integration of the peak area under the curve from the specific precursor ions of the analytes and their internal standards. The response (the ratio of the integrated area of the analyte and the corresponding IS) was compared to the calibration curve. The IS chosen for each analyte, retention times, and precursor ions are shown in Table 2.

For screening, the data were assessed by the screening software ChromaLynx XS (Waters Corporation, Milford, USA). In this software the fragments in Function 2 play an important role for the identification of compounds compared to a larger compound library/database. This will not be discussed further in this paper, but is presented by Pedersen, et al. [12].

\section{Calibration curve}

Calibration in whole blood was evaluated. The concentration points were $0,0.001,0.002,0.005,0.01,0.02,0.05,0.1,0.2,0.5$, and $1.0 \mathrm{mg} / \mathrm{kg}$. Calibrators were prepared in $200 \mu \mathrm{L}$ of whole blood spiked with $25 \mu \mathrm{L}$ standard and $20 \mu \mathrm{L}$ IS. Three examples of calibration curves are shown in Figure 2.

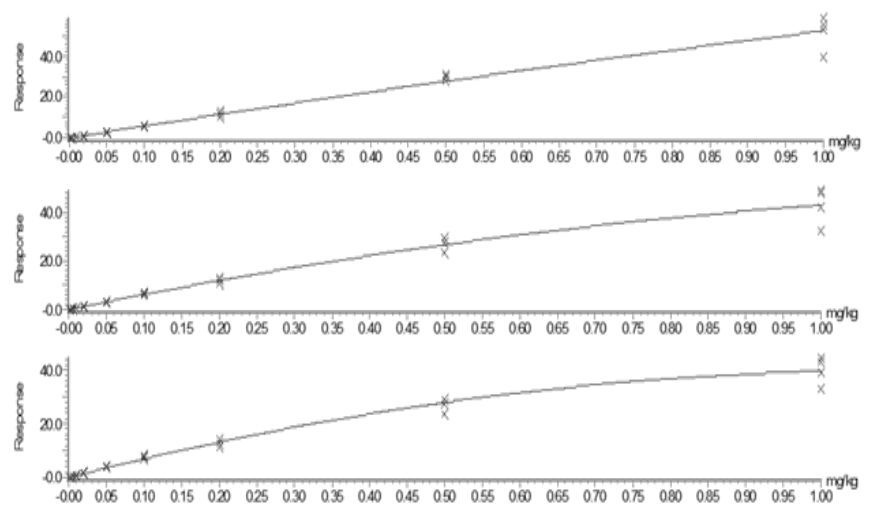

Figure 2: Examples of calibration curves. 7-aminonitrazepam (top), diazepam (middle) and ketobemidone (bottom).

\section{Matrix effects and extraction recoveries}

Matrix effects (ME) and extraction recoveries for whole blood were evaluated on the basis of peak area responses [18,19]. Seven authentic case samples (four autopsy cases and three traffic cases) and two blank blood samples (blood bank samples) were used. All samples were screened negative for a broad variety of drugs including drugs of abuse. Two sets of the nine whole blood samples were extracted according to the SPE procedure. The first set was spiked with 30 analytes after the SPE extraction (B), and the second set was spiked before extraction $(\mathrm{C})$ to a corresponding concentration in whole blood. The $\mathrm{B}$ and $\mathrm{C}$ experiments were performed in duplicate for all nine samples. Thus, nine replicates of a reference solution (A) also prepared in acidified methanol were analyzed directly with the UPLC-TOF-MS system. The $\mathrm{ME}$ results obtained in this study were calculated as follows:

Eq. $1: \operatorname{ME}(\%)=(1-(B / A)) \times 100 \%$,

where A equals the peak area of standards in mobile phase and $B$ is the peak area obtained for whole blood samples spiked with analytes after extraction. An ME value $>0$ indicates ionization suppression and a value $<0$ indicates ionization 


\begin{tabular}{|c|c|c|c|c|c|c|c|c|c|c|c|c|}
\hline \multirow[t]{2}{*}{ Analyte } & \multirow{2}{*}{$\begin{array}{r}\text { Internal } \\
\text { standard }\end{array}$} & \multirow{2}{*}{$\begin{array}{l}{[\mathrm{M}+\mathbf{H}] \mathbf{1}+\mathbf{1}^{\star} \mathbf{1}} \\
\mathrm{m} / \mathrm{z}\end{array}$} & \multirow{2}{*}{$\begin{array}{r}\text { RT } \\
\text { Min }\end{array}$} & \multirow{2}{*}{$\begin{array}{r}\text { Range } \\
\mathrm{mg} / \mathrm{kg}\end{array}$} & \multirow{2}{*}{$\begin{array}{l}\text { LOD } \\
\mathrm{mg} / \mathrm{kg}\end{array}$} & \multicolumn{3}{|l|}{ LOQ } & \multicolumn{2}{|l|}{$>$ LOQ } & \multirow{2}{*}{$\begin{array}{l}\text { RE } \\
\%\end{array}$} & \multirow{2}{*}{$\begin{array}{l}\text { ME } \\
\%\end{array}$} \\
\hline & & & & & & $\mathrm{mg} / \mathrm{kg}$ & Precision & Accuracy & Precision & Accuracy & & \\
\hline 6-MAM & 6-MAM D6 & 328.1549 & 2.03 & $0.02-1.0$ & 0.0026 & 0.02 & 5 & 85 & $2-7$ & $87-115$ & 89 & 15 \\
\hline $\begin{array}{l}\text { 7-aminoclo- } \\
\text { nazepam }\end{array}$ & $\begin{array}{l}\text { 7-aminoclon- } \\
\text { azepam D4 }\end{array}$ & 286.0747 & 3.67 & $0.02-0.5$ & 0.0049 & 0.02 & 9 & 88 & $7-15$ & 89-106 & 41 & -1 \\
\hline $\begin{array}{l}\text { 7-aminoflu- } \\
\text { nitrazepam }\end{array}$ & $\begin{array}{l}\text { 7-aminofluni- } \\
\text { trazepam D3 }\end{array}$ & 284.1199 & 4.50 & $0.02-1.0$ & 0.0041 & 0.02 & 8 & 84 & $4-8$ & $85-114$ & 47 & -4 \\
\hline $\begin{array}{l}\text { 7-aminoni- } \\
\text { trazepam }\end{array}$ & $\begin{array}{l}\text { 7-aminoni- } \\
\text { trazepam D5 }\end{array}$ & 252.1137 & 2.08 & $0.05-1.0$ & 0.0232 & 0.05 & 16 & 99 & $6-11$ & $94-113$ & 64 & 50 \\
\hline Alprazolam & $\begin{array}{l}\text { Alprazolam } \\
\text { D5 }\end{array}$ & 309.0907 & 8.53 & $0.02-0.5$ & 0.0059 & 0.02 & 12 & 82 & $4-10$ & $91-108$ & 91 & -7 \\
\hline $\begin{array}{l}\text { Ampheta- } \\
\text { mine }\end{array}$ & $\begin{array}{l}\text { Amphetamine } \\
\text { D5 }\end{array}$ & 136.1126 & 2.15 & $0.005-1.0$ & 0.0016 & 0.005 & 12 & 86 & $7-12$ & 91-103 & 91 & 13 \\
\hline $\begin{array}{l}\text { Benzo- } \\
\text { ylecgonine }\end{array}$ & $\begin{array}{l}\text { Benzoylecgo- } \\
\text { nine D8 }\end{array}$ & 290.1392 & 2.89 & $0.02-1.0$ & 0.0010 & 0.02 & 2 & 90 & $5-10$ & $103-112$ & 102 & -5 \\
\hline $\begin{array}{l}\text { Bromaz- } \\
\text { epam }\end{array}$ & $\begin{array}{l}\text { Bromazepam } \\
\text { D4 }\end{array}$ & 316.0085 & 6.42 & $0.02-1.0$ & 0.0064 & 0.02 & 12 & 87 & $1-11$ & $97-103$ & 97 & -5 \\
\hline Cathine & Ephedrine D3 & 152.1075 & 1.44 & $0.005-1.0$ & 0.0020 & 0.005 & 15 & 97 & $9-13$ & $95-112$ & 100 & 28 \\
\hline Cathinone & Ephedrine D3 & 150.0919 & 1.52 & $0.02-1.0$ & 0.0093 & 0.02 & 15 & 101 & $11-15$ & $98-107$ & 109 & 39 \\
\hline $\begin{array}{l}\text { Chlordiaz- } \\
\text { epoxide }\end{array}$ & $\begin{array}{l}\text { Chlordiaz- } \\
\text { epoxide D5 }\end{array}$ & 300.0904 & 5.69 & $0.05-1.0$ & 0.0033 & 0.02 & 7 & 81 & $4-10$ & $90-113$ & 105 & 1 \\
\hline Clonazepam & $\begin{array}{l}\text { Clonazepam } \\
\text { D4 }\end{array}$ & 316.0489 & 8.20 & $0.05-1.0$ & 0.0263 & 0.02 & 18 & 98 & $10-15$ & $96-103$ & 73 & -7 \\
\hline Cocaine & Cocaine D3 & 304.1549 & 4.38 & $0.02-1.0$ & 0.0058 & 0.02 & 11 & 88 & $3-13$ & $90-114$ & 109 & 1 \\
\hline Codeine & Codeine D6 & 300.1600 & 1.62 & $0.02-1.0$ & 0.0021 & 0.02 & 4 & 83 & $2-6$ & $89-113$ & 109 & 18 \\
\hline Diazepam & Diazepam D5 & 285.0795 & 10.50 & $0.02-0.5$ & 0.0035 & 0.02 & 7 & 82 & $5-10$ & $92-111$ & 89 & -3 \\
\hline $\begin{array}{l}\text { Flunitraz- } \\
\text { epam }\end{array}$ & $\begin{array}{l}\text { Flunitraz- } \\
\text { epam D3 }\end{array}$ & 314.0941 & 8.86 & $0.05-1.0$ & 0.0130 & 0.05 & 9 & 95 & $5-10$ & $88-111$ & 77 & -7 \\
\hline Ketamine & Ketamine D4 & 238.0999 & 3.08 & $0.02-1.0$ & 0.0017 & 0.02 & 3 & 86 & $2-5$ & 98-109 & 111 & 3 \\
\hline $\begin{array}{l}\text { Ketobemi- } \\
\text { done }\end{array}$ & $\begin{array}{l}\text { Benzoylecgo- } \\
\text { nine D8 }\end{array}$ & 248.1651 & 2.65 & $0.02-0.5$ & 0.0014 & 0.02 & 3 & 96 & $2-12$ & 104-109 & 109 & 11 \\
\hline MDA & MDA D5 & $163.0759^{\star} 2$ & 2.20 & $0.02-0.5$ & 0.0039 & 0.02 & 7 & 98 & $11-14$ & $92-104$ & 97 & -8 \\
\hline MDMA & MDMA D5 & 194.1181 & 2.43 & $0.02-1.0$ & 0.0021 & 0.02 & 4 & 86 & $5-11$ & $93-113$ & 66 & 5 \\
\hline $\begin{array}{l}\text { Metham- } \\
\text { phetamine }\end{array}$ & $\begin{array}{l}\text { Methamphet- } \\
\text { amine D5 }\end{array}$ & 150.1283 & 2.42 & $0.02-1.0$ & 0.0020 & 0.02 & 4 & 87 & $6-8$ & 89-112 & 47 & 3 \\
\hline Methadone & $\begin{array}{l}\text { Methadone } \\
\text { D3 }\end{array}$ & 310.2171 & 8.37 & $0.02-1.0$ & 0.0105 & 0.02 & 6 & 106 & $3-7$ & $89-110$ & 103 & -12 \\
\hline Morphine & Morphine D6 & 286.1443 & 1.12 & $0.02-1.0$ & 0.0068 & 0.02 & 11 & 100 & 5-14 & 94-115 & 78 & 27 \\
\hline Nitrazepam & $\begin{array}{l}\text { Nitrazepam } \\
\text { D5 }\end{array}$ & 282.0879 & 7.77 & $0.05-1.0$ & 0.0177 & 0.05 & 15 & 82 & $3-10$ & $90-92$ & 83 & 1 \\
\hline $\begin{array}{l}\text { Nordiaz- } \\
\text { epam }\end{array}$ & $\begin{array}{l}\text { Nordiazepam } \\
\text { D5 }\end{array}$ & 271.0638 & 9.03 & $0.02-0.5$ & 0.0036 & 0.02 & 7 & 88 & $5-11$ & $102-115$ & 94 & -1 \\
\hline Oxazepam & Oxazepam D5 & 287.0587 & 7.93 & $0.02-1.0$ & 0.0079 & 0.02 & 13 & 100 & $2-13$ & 93-106 & 67 & -11 \\
\hline Temazepam & $\begin{array}{l}\text { Temazepam } \\
\text { D5 }\end{array}$ & 301.0744 & 9.21 & $0.02-0.5$ & 0.0096 & 0.02 & 17 & 93 & $11-13$ & 85-109 & 81 & -13 \\
\hline Tramadol & Tramadol D3 & 264.1964 & 3.82 & $0.02-1.0$ & 0.0060 & 0.02 & 11 & 94 & $4-10$ & $91-112$ & 108 & 2 \\
\hline $\begin{array}{l}\text { O-Des- } \\
\text { methyltra- } \\
\text { madol }\end{array}$ & $\begin{array}{l}\text { O-Desmethyl- } \\
\text { tramadol D6 }\end{array}$ & 250.1807 & 2.24 & $0.02-1.0$ & 0.0022 & 0.02 & 4 & 84 & $2-5$ & $91-112$ & 108 & 6 \\
\hline Zolpidem & Zolpidem D6 & 308.1763 & 4.74 & $0.02-0.5$ & 0.0025 & 0.02 & 5 & 91 & $3-11$ & $104-105$ & 105 & -1 \\
\hline
\end{tabular}

${ }^{11}$ There is a difference of around $0.5 \mathrm{mDa}$ between the theoretical mass and the calculated mass, as the software adds the mass of a hydrogen atom instead of the mass of a proton ${ }^{2}$ product ion i Function 2

Table 2: Identification and validation parameters. 
enhancement.

Extraction recoveries (RE) were calculated as:

Eq. $2: \operatorname{RE}(\%)=(\mathrm{C} / \mathrm{B}) \times 100 \%$

\section{Precision and accuracy}

Evaluation of precision and accuracy were based on the ISO 17025 guideline [20]. To evaluate precision and accuracy, we analyzed four replicates at seven concentration levels on two different days $(n=8)$. The seven concentration levels analyzed were: $0.002,0.005,0.02,0.05,0.2,0.5$, and $1.0 \mathrm{mg} / \mathrm{kg}$. A calibrator series was freshly prepared for every run, based on $0.200 \mathrm{~g}$ of whole blood spiked with all analytes, yielding the concentration points: $0.005,0.05$, and $0.5 \mathrm{mg} / \mathrm{kg}$. Prior to analysis, seven different stock samples ( $5 \mathrm{~g}$ each) representing the seven concentration levels were prepared by spiking pooled whole blank blood with all of the analytes. On day one of analysis, four samples ( $0.200 \mathrm{~g}$ of blood) were taken from each of the seven stock samples. All 16 samples (four replicates for each concentration level) and the calibrators were spiked with $20 \mu \mathrm{L}$ of IS, as described above, and subjected to SPE. The procedure was repeated on day two of analysis. Another spiked sample at a concentration level of $0.001 \mathrm{mg} / \mathrm{kg}$ was prepared and used for the determination of limit of detection (LOD). Four replicates were analyzed. This procedure was repeated the next day, and LOD was calculated from the eight results as 3 standard deviations.

\section{Results and discussion}

\section{Quantification by UHPLC-TOF-MS}

The chromatographic separation method used in this study was originally developed by Humbert, et al. [15]. and has been successfully used by us and others [15-17]. Setting up a quantification method on a TOF instrument is relatively easy as compared to a quadrupole MS/MS instrument. The lower resolving power of the MS/MS apparatus requires that the compounds of interest be 'tuned' to determine the specific MRM transitions by optimizing the cone voltage and the collision energy. In contrast, with TOF in data-independent acquisition $\left(\mathrm{MS}^{\mathrm{E}}\right)$ mode, universal values for cone and collision energy are applied. We found that the optimal capillary voltage should be set at a very low voltage $(0.3 \mathrm{kV})$. A low capillary voltage optimizes the sensitivity for low molecular mass compounds like amphetamine, MDA, MDMA, cathine and cathinone, without losing too much sensitivity for the rest of the target compounds. Also the cone voltage was set to a low voltage $(20 \mathrm{~V})$ because of the low molecular mass compounds.

A significant benefit of TOF instrumentation is that all of the data is collected. In contrast, with a MS/MS instrument operated in MRM mode, quantitative information that is acquired during an analytical run is derived from only restricted channels of data. Thus, the original dataset from TOF analysis also offers the opportunity of performing an expanded screen, against a larger database using suitable software. In our laboratory the screening software ChromaLynx XS is used to screen for more than 850 compounds. In a previous study we demonstrated how the fragment data (Function 2) can be used for screening of 256 drugs [12].

\section{Validation}

Concerning calibration, we investigated the analyte/IS peak area response ratio in whole blood (Table 2). The calibration curves were slightly curved and fitted to a quadratic regression curve using weighting $(1 / \mathrm{X})$, where the coefficient for the quadratic term deviated significantly from zero $(\mathrm{P}<0.01)$ for all compounds. The calibration range obtained for all analytes in blood started at $0.02 \mathrm{mg} / \mathrm{kg}$ except for amphetamine and cathine, which started at $0.005 \mathrm{mg} / \mathrm{kg}$ (Table 2), and 7- aminonitrazepam, chlordiazepoxide, clonazepam, flunitrazepam and nitrazepam, which started at $0.05 \mathrm{mg} /$ $\mathrm{kg}$. The calibration range for all analytes extended to $1.0 \mathrm{mg} /$ $\mathrm{kg}$, except for 7- aminoclonazepam, alprazolam, diazepam, ketobemidone, MDA, nordiazepam, temazepam and zolpidem, where $0.5 \mathrm{mg} / \mathrm{kg}$ was the upper limit. Fig. 2 displays examples of calibration curves. The curve of 7-aminonitrazepam was only slightly curved, and the upper measurement limit without dilution was $1 \mathrm{mg} / \mathrm{kg}$. The curves for diazepam and ketobemidone were somewhat more curved, and the upper measurement limits were $0.5 \mathrm{mg} / \mathrm{kg}$.

Matrix effects and extraction recoveries for the 30 tested analytes are listed in Table 2 as the mean of the nine samples. MEs were higher for early eluting compounds ( $\mathrm{RT}<3 \mathrm{~min})$. The MEs were within $\pm 50 \%$, and so we concluded that ME was of minor significance because of the use of internal standards. Extraction recoveries were estimated to $41 \%-111 \%$, which are better or correspond to those of recently published methods for drugs of abuse in whole blood [21,22]. The LOQ was determined as the lowest concentration yielding precision (CV) of $\leq 20 \%$ and bias of $\pm 20 \%$ with fulfillment of retention time and $5 \mathrm{mDa}$ mass tolerances. The $\mathrm{CV}$ and accuracy were determined for at least four concentration levels. The precision and accuracy were generally accepted at a maximum of $15 \%$ (LOQ 20\%). All analytes fulfilled the precision criteria at all concentration levels. The validation procedure in the present study was primarily based on the ISO17025 guideline, because our laboratory is accredited, and the present work was in progress, when the new SWGTOX guideline was published [23].

\section{Comparison of UHPLC-TOF-MS quantitative performance with UHPLC-MS/MS performance}

UHPLC-MS/MS is generally the method of choice for quantitative determination, characterized by high sensitivity, large dynamic range and good precision [11]. Although the TOF technique as shown above provided good quantitative determination of the compounds, it is of interest to relate the specifications to that of UHPLC-MS/MS. We recently published an UHPLC-MS/MS method for about the same 30 compounds considered here [13]. For most compounds, the LOQ is about ten times lower for the UHPLC-MS/MS method than for the present UHPLC-TOF-MS method, and the dynamic range is correspondingly wider. Precision and accuracy were about similar for the two methods. Thus, it is no doubt that UHPLCMS/MS is the optimal approach with regard to quantification, but the TOF approach still performs reasonable and at the same time has a screening potential outperforming the UHPLC-MS/ MS approach. 


\section{Conclusion}

The present study showed that the UHPLC-TOF-MS technique is useful for quantitative determination of common drugs of abuse in blood, which can be carried out simultaneously with a comprehensive general screening for drugs. Thus, it is possible to combine screening with quantitative determination of the main drugs of interest providing a very efficient approach for screening and quantification in toxicology.

\section{Acknowledgements}

The authors would like to acknowledge Martin S. Frederiksen, Birthe Christensen, and Jonas T. Froholdt for help in the laboratory. The authors would also like to acknowledge Michelle Wood (Waters MS Technologies Centre, Manchester, U.K.) for valuable advice.

\section{References}

1. Bassan DM, Erdmann F, Krull R (2011) Quantitative determination of 43 common drugs and drugs of abuse in human serum by HPLC -MS/MS. Anal Bioanal Chem 400: 43-50.

2. Remane D, Meyer MR, Wissenbach DK, Maurer HH (2011) Full validation and application of an ultra high performance liquid chromatographic-tandem mass spectrometric procedure for target screening and quantification of 34 antidepressants in human blood plasma as part of a comprehensive multianalyte approach. Anal Bioanal Chem 400: 2093-107.

3. Dalsgaard PW, Rasmussen BS, Muller IB, Linnet K (2012) Toxicological screening of basic drugs in whole blood using UPLC-TOF-MS. Drug Test Anal 4: 313-9.

4. Pelander A, Ristimaa J, Rasanen I, Vuori E, Ojanpera I (2008) Screening for basic drugs in hair of drug addicts by liquid chromatography/time-of-flight mass spectrometry. Ther Drug Monit 30: 717-24.

5. Broecker S, Herre S, Wust B, Zweigenbaum J, Pragst F (2011) Development and practical application of a library of CID accurate mass spectra of more than 2,500 toxic compounds for systematic toxicological analysis by LCQTOF-MS with data-dependent acquisition. Anal Bioanal Chem 400: 101-17.

6. Lee HK, Ho CS, Iu YP, Lai PS, Shek CC, et al. (2009) Development of a broad toxicological screening technique for urine using ultra-performance liquid chromatography and time-of-flight mass spectrometry. Anal Chim Acta 649: 80-90.

7. Polettini A, Gottardo R, Pascali JP, Tagliaro F (2008) Implementation and performance evaluation of a database of chemical formulas for the screening of pharmaco/toxicologically relevant compounds in biological samples using electrospray ionization-time-of-flight mass spectrometry. Anal Chem 80: 3050-7.

8. Nielsen MK, Johansen SS, Dalsgaard PW, Linnet K (2010) Simultaneous screening and quantification of 52 common pharmaceuticals and drugs of abuse in hair using UPLC-TOF-MS. Forensic Sci Int 196: 85-92.
9. ElSohly MA, Gul W, Murphy TP, Avula B, Khan IA (2007) LC-(TOF) MS analysis of benzodiazepines in urine from alleged victims of drug-facilitated sexual assault. J Anal Toxicol 31: 505-14.

10. Ojanpera I, Kolmonen M, Pelander A (2012) Current use of high-resolution mass spectrometry in drug screening relevant to clinical and forensic toxicology and doping control. Anal Bioanal Chem 403: 1203-20.

11. Peters FT (2011) Recent advances of liquid chromatography-(tandem) mass spectrometry in clinical and forensic toxicology. Clin Biochem 44: 54-65.

12. Pedersen AJ, Dalsgaard PW, Rode AJ, Rasmussen BS, Muller IB, et al. (2013) Screening for illicit and medicinal drugs in whole blood using fully automated SPE and ultra-high-performance liquid chromatography with TOF-MS with data-independent acquisition. J Sep Sci 36: 2081-9.

13. Bjork MK, Simonsen KW, Andersen DW, Dalsgaard PW, Siguroardottir SR, et al. (2013) Quantification of 31 illicit and medicinal drugs and metabolites in whole blood by fully automated solid-phase extraction and ultra-performance liquid chromatography-tandem mass spectrometry. Anal Bioanal Chem 405: 2607-17.

14. Andersen D, Rasmussen B, Linnet K (2012) Validation of a fully automated robotic setup for preparation of whole blood samples for LC-MS toxicology analysis. J Anal Toxicol 36: 280-7.

15. Humbert L, Grisel F, Richeval C, Lhermitte M (2010) Screening of xenobiotics by ultra-performance liquid chromatography-mass spectrometry using in-source fragmentation at increasing cone voltages: library constitution and an evaluation of spectral stability. J Anal Toxicol 34: 571-80.

16. Rosano TG, Wood M, Swift TA (2011) Postmortem drug screening by non-targeted and targeted ultra-performance liquid chromatography-mass spectrometry technology. J Anal Toxicol 35: 411-23.

17. Dalsgaard PW, Rode AJ, Pedersen AJ, Rasmussen BS, Windberg CN, et al. (2013) Screening of 30 acidic and neutral pharmaceuticals in whole blood by fully automated SPE and UPLC-TOF-MS(E.). Drug Test Anal 5: 254-8.

18. Matuszewski BK, Constanzer ML, Chavez-Eng CM (2013) Strategies for the assessment of matrix effect in quantitative bioanalytical methods based on HPLC-MS/MS. Anal Chem 75: 3019-30.

19. Peters FT, Drummer OH, Musshoff F (2007) Validation of new methods. Forensic Sci Int 165: 216-24.

20. ISO/IEC 17025 (2005) General requirements for the competence of testing and calibration laboratories. International Organization for Standardization, Geneva.

21. Birkler RI, Telving R, Ingemann-Hansen O, Charles AV, Johannsen M, et al. (2012) Screening analysis for medicinal drugs and drugs of abuse in whole blood using ultra-performance liquid chromatography time-of-flight mass spectrometry (UPLC-TOF-MS)-toxicological findings in cases of alleged sexual assault. Forensic Sci Int 222: 154-61.

22. Verplaetse R, Tytgat J (2012) Development and validation of a sensitive UPLC-MS/MS method for the analysis of narcotic analgesics in urine and whole blood in forensic context. Forensic Sci Int 215: 136-45.

23. Standard Practices for Method Validation in Forensic Toxicology (2013) Scientific Working Group for Forensic Toxicology (SWGTOX).

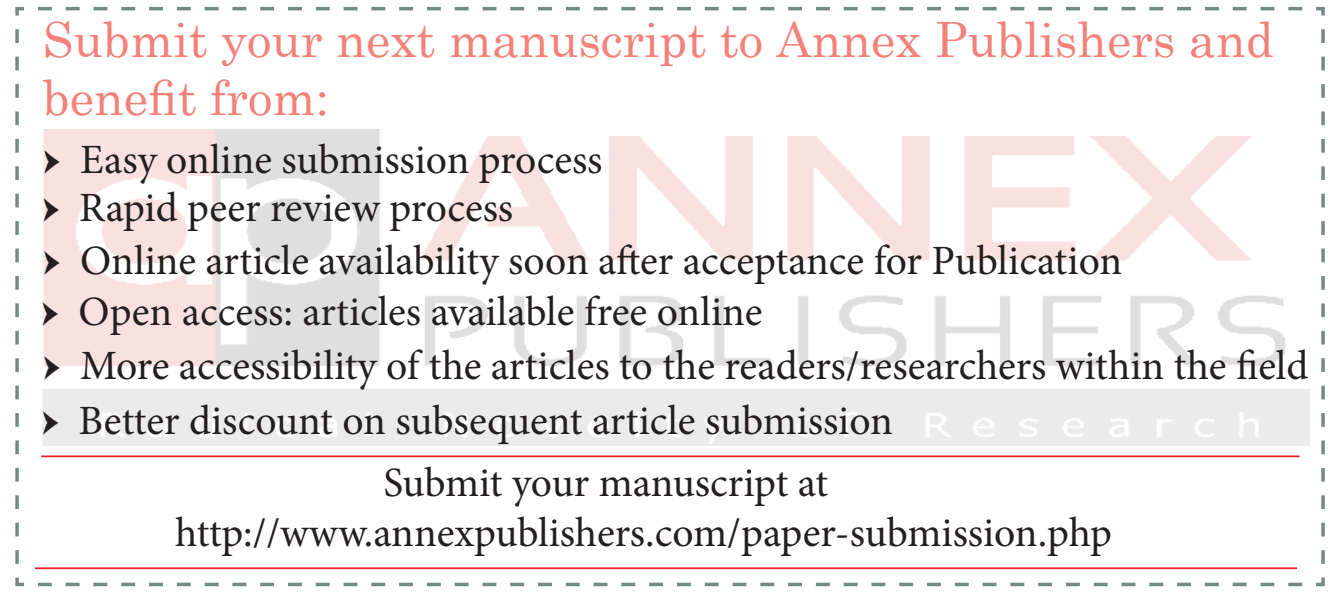

